\title{
Factors Affecting the Binding of Bilirubin to Serum Albumins: Validation and Application of the Peroxidase Method
}

\author{
LESLYE ROCA, SEBASTIÁN CALLIGARIS, RICHARD P. WENNBERG, CHARLES E. AHLFORS, SAFARINA G. MALIK, \\ J. DONALD OSTROW, AND CLAUDIO TIRIBELLI
}

\begin{abstract}
Centro Studi Fegato, Department of Biochima, Biofisica Chimica, Marcomolecole [L.R., S.C., C.T.], AREA Science Park, University of Trieste, 34012 Trieste, Italy; Department of Pediatrics [R.P.W.], Department of Medicine [J.D.O.], University of Washington, Seattle, WA, 98195; Vashon, WA, 98070 [C.E.A]; Eijkman Institute for Molecular Biology [S.G.M.], Jakarta 10430, Indonesia
\end{abstract}

\begin{abstract}
The unbound "free" bilirubin concentration $\left(\mathrm{B}_{\mathrm{f}}\right)$, not the total bilirubin concentration, is the critical determinant of cellular uptake and toxicity of bilirubin. We compared $\mathrm{B}_{\mathrm{f}}$ measured by a modified peroxidase method with published data obtained with ultrafiltration and examined conditions that affect the affinity $\left(\mathrm{K}_{\mathrm{F}}\right)$ of human (HSA) and bovine (BSA) serum albumin for bilirubin. The peroxidase and ultrafiltration methods yielded similar $\mathrm{K}_{\mathrm{F}}$ values that decreased with increasing HSA concentration and the presence of 50 $\mathrm{mM}$ chloride. When related to ionic strength, inhibition of BSAbilirubin binding by chloride, bromide, and sulfate were similar, whereas phosphate buffer had a smaller effect. $\mathrm{K}_{\mathrm{F}}$ was lower at $37^{\circ} \mathrm{C}$ than at $25^{\circ} \mathrm{C}$ for HSA but not for BSA. $\mathrm{K}_{\mathrm{F}}$ for BSA was similar at $\mathrm{pH}$ 7.4 and 8.0. BSA and FCS had similar binding properties. The close agreement of $\mathrm{B}_{\mathrm{f}}$ and $\mathrm{K}_{\mathrm{F}}$ values determined by the peroxidase method with published results obtained by ultrafiltration validates both methods and supports the use of the peroxidase method as a practical technique for measuring $B_{f}$ under steady state conditions in minimally diluted serum or culture medium. (Pediatr Res 60: 724-728, 2006)
\end{abstract}

$\mathrm{T}$ The unbound ("free") concentration of unconjugated bilirubin $\left(\mathrm{B}_{\mathrm{f}}\right)$ in plasma, although less than $0.1 \%$ of total bilirubin concentration, is the principal determinant of tissue uptake and toxicity of bilirubin, and plays a critical role in the pathogenesis of bilirubin encephalopathy in jaundiced newborns $(1,2)$ and in patients with Crigler Najjar disease (3). Notwithstanding its biologic significance, $\mathrm{B}_{\mathrm{f}}$ has rarely been measured in either clinical evaluation of jaundiced newborns or in vitro studies of bilirubin effects and toxicity. This avoidance is due in part to the perceived complexity of $\mathrm{B}_{\mathrm{f}}$ assays and scepticism regarding their clinical value or accuracy (4-6).

Bilirubin-albumin binding has been studied using a variety of techniques, including fluorescent quenching, bilirubin fluorescence, circular dichroism, Sephadex gel filtration, optical rotary dispersion, dialysis, ultrafiltration, spectrophotometry, and enzymatic oxidation of bilirubin (peroxidase method). Reported association constants for HSA range from $6.7 \times 10^{6}$

Received May 18, 2006; accepted August 3, 2006.

Correspondence: Richard P. Wennberg, M.D., Division of Neonatology Department of Pediatrics, Box 356320 University of Washington Medical Center, 1959 NE Pacific Street, Seattle, WA 98195-6320; e-mail: rpwennberg@hotmail.com

Partially supported by grants from Telethon, Italy (GGP05062), and from Fondazione Cassa Risparmio, Trieste, Italy (FCRT 03-01). LR and SC were supported by fellowships from Ministero Affari Esteri, Rome, Italy. RPW was supported by a Senior Fellowship from AREA Science Park, Trieste, Italy.
$\mathrm{M}^{-1}$ to $>10^{8} \mathrm{M}^{-1}$ (7-10). The binding constant of HSA has been estimated to be 2-13 times greater than that of BSA (11-13). Considerable variation in serum binding of bilirubin has been reported in newborn infants (2). These differences may be due to direct binding competitors (e.g. sulfonamides), allosteric effects, electrolyte environment, or simply the assay technique, e.g. serum sample dilution (14).

The dependency of bilirubin binding affinity on HSA concentration as well as chloride concentration was demonstrated by Weisiger et al. (15) using a complicated procedure in which binding affinity of ${ }^{14} \mathrm{C}$-bilirubin was calculated after the sequential removal of labeled impurities by serial ultrafiltration. A more practical technique for measuring $\mathrm{B}_{\mathrm{f}}$ in clinical or laboratory settings was developed by Jacobsen and Wennberg (16) based on the observation that albumin-binding protects bilirubin from oxidation by HRP. Ahlfors $(14,17)$ has modified the peroxidase method, emphasizing the need to measure $\mathrm{B}_{\mathrm{f}}$ with two or more HRP concentrations and under the same conditions and albumin concentrations existing in plasma or incubation medium.

In this investigation, we replicated and extended the experimental conditions used in ultrafiltration studies (15) and examined the effects of albumin and electrolyte concentrations on bilirubin binding to HSA and BSA, using the modified peroxidase method (17). We then evaluated various experimental conditions that must be controlled when measuring $B_{f}$ in tissue culture medium.

\section{MATERIALS AND METHODS}

Materials. PBS, DMEMHG, penicillin, and streptomycin were purchased from Euroclone, Milan, Italy. FCS, obtained from Invitrogen (Carlsbad, CA), contained $24 \mathrm{~g} / \mathrm{L}$ albumin. Chloroform, HPLC grade was obtained from Carlo Erba, Milan, Italy. Bilirubin, DMSO (HPLC grade), HRP (EC.1.11.1.7/P 8125, Type I), hydrogen peroxide $\left(\mathrm{H}_{2} \mathrm{O}_{2}, 30 \% \mathrm{wt} / \mathrm{vol}\right)$, fatty acid-free HSA, and fatty acid-free BSA fraction V, were purchased from Sigma Chemical Co.-Aldrich, Milan, Italy.

Abbreviations: B, total unconjugated bilirubin concentration; B/A, molar ratio of bilirubin to albumin; DMEMHG, Dulbecco's modified Eagle's medium-high glucose; HRP, horseradish peroxidase; HSA, human serum albumin; $\mathbf{K}_{\mathbf{F}}$, calculated equilibrium binding constant of bilirubin to albumin; $\mathbf{k p}$, first-order rate constant for the oxidation of bilirubin by HRP

DOI: 10.1203/01.pdr.0000245992.89965.94 
Preparation of solution and reagents. Bilirubin was purified using the method of McDonagh and Assisi (18), divided into $50 \mu \mathrm{g}$ aliquots, and stored at $-20^{\circ} \mathrm{C}$ until used. Aliquots were dissolved in either $200 \mu \mathrm{L} 0.01 \mathrm{~N} \mathrm{NaOH}$, followed by dilution with $2.64 \mathrm{~mL} \mathrm{H}_{2} \mathrm{O}$ (final concentration $30 \mu \mathrm{M}$ ) or $17 \mu \mathrm{L}$ DMSO, yielding $5 \mathrm{mM}(3 \mu \mathrm{g} / \mathrm{mL})$.

Immediately after preparation, the bilirubin stock solution was added to PBS or DMEMHG containing 30 or $60 \mu \mathrm{M}$ HSA or BSA, or 10\% FCS (33 $\mu \mathrm{M}$ BSA). Final DMSO concentrations never exceeded $0.5 \%$ (vol $/ \mathrm{vol})$. When $\mathrm{NaOH}$ stock was added, the $\mathrm{pH}$ was adjusted to 7.4 with $0.01 \mathrm{~N} \mathrm{HCl}$. Total bilirubin concentrations (B) in albumin solutions were confirmed by the absorbance (A) at $468 \mathrm{~nm}$ (BSA) or $460 \mathrm{~nm}$ (HSA) assuming $\varepsilon^{1 \mathrm{~cm}}=49,000$ $\mathrm{A} / \mathrm{mol}$ for BSA and 48,000 A/mol for HSA (16).

HRP stock solution $(1 \mathrm{mg} / \mathrm{mL})$ was prepared by dissolving $2 \mathrm{mg}$ HRP (EC.1.11.1.7/P 8125, Type I) in $2 \mathrm{~mL}$ PBS, pH 7.4, and stored at $-20^{\circ} \mathrm{C}(19)$.

$1.0 \%$ Hydrogen peroxide was prepared freshly each day by diluting $1 \mathrm{~mL}$ $30 \% \mathrm{H}_{2} \mathrm{O}_{2}$ with $29 \mathrm{~mL}$ PBS.

Peroxidase method-basic principles and calculations. Unbound bilirubin is oxidized to mostly colorless compounds by peroxide $\left(\mathrm{H}_{2} \mathrm{O}_{2}\right)$ in the presence of HRP with first-order kinetics; albumin-bound bilirubin is not oxidized. The rate constant for oxidation of bilirubin by HRP (kp) is determined by measuring the decrease in $\mathrm{A}_{440}$ following addition of HRP and $\mathrm{H}_{2} \mathrm{O}_{2}$ to dilute solutions of bilirubin $(1-3 \mu \mathrm{M})$ :

$$
k p=V_{o} /\left(\left[B_{f}\right] \times[H R P]\right)
$$

Vo, the initial oxidation velocity determined using a recording spectrophotometer, can be expressed either as the initial decrease in total bilirubin concentration (B) or simply $\Delta \mathrm{A}_{440} / \min \left(\right.$ i.e. $\left.\mathrm{A}_{\mathrm{o}}-\mathrm{A}_{\mathrm{t}}\right) / \mathrm{t}$ :

$$
k p=\frac{\Delta A}{A_{\mathrm{o}}[H R P] \cdot \Delta t}\left(\mathrm{~mL} \cdot \mu \mathrm{g}^{-1} \cdot \min ^{-1}\right)
$$

Alternatively, kp may be calculated from an integrated form of eq. (1), which accounts for nonlinear oxidation as B decreases:

$$
k p=-\frac{\ln \left(\frac{A_{t}}{A_{o}}\right)}{[H R P] \cdot t}
$$

The steady state $\mathrm{B}_{\mathrm{f}}$ in bilirubin-albumin solutions is determined by measuring the decrease in $\mathrm{A}_{460}$ (HSA) or $\mathrm{A}_{468}$ (BSA) over 30-60 $\mathrm{s}$ in the presence of $\mathrm{HRP}$ and $\mathrm{H}_{2} \mathrm{O}_{2}$ and calculated from the rate constant (kp), the concentration of HRP, and the initial change in bilirubin concentration (or $\Delta \mathrm{A})$ over time.

$$
\beta_{f \text { SteadyState }}=\frac{\Delta A}{\varepsilon * \cdot k p \cdot[H R P] \cdot \Delta t}
$$

where $\varepsilon^{*}$ is the molar absorbance coefficient of bilirubin-albumin (BSA or HSA), or with the integrated form:

$$
\beta_{\text {fSteadyState }}=\frac{A_{o} \cdot \ln \left(\frac{A_{t}}{A_{o}}\right)}{\varepsilon^{*} \cdot k p \cdot[H R P] \cdot t}
$$

The instantaneous decrease in $\mathrm{A}_{460}$ (HSA) or $\mathrm{A}_{468}$ (BSA) reflects the equilibrium $\mathrm{B}_{\mathrm{f}}$, but thereafter the rate of oxidation represents the steady state concentration of $\mathrm{B}_{\mathrm{f}}$ reflecting bilirubin-albumin association/dissociation and enzyme oxidation $(14,17)$. To determine the equilibrium $B_{f}$, the assay is performed with at least two concentrations of enzyme. As the bilirubin/ albumin molar ratio (B/A) increases, albumin-bilirubin dissociation becomes rate limiting, and a significant underestimation of $B_{f}$ will occur if several concentrations of HRP are not used. Because $1 /\left[\right.$ steady-state $\left.B_{f}\right]$ is proportional to $1 /\left(\left[\mathrm{B}_{\mathrm{f}}\right]+[\mathrm{HRP}]\right)$, the equilibrium $\mathrm{B}_{\mathrm{f}}$ is determined from the inverse of the $y$ intercept of a plot of 1/[steady-state $\left.\mathrm{B}_{\mathrm{f}}\right]$ versus [HRP] (17).

The binding constant was calculated assuming a single albumin binding site because measurements were performed at low B/A ratios (0.2-0.3), where binding to other sites should be minimal (15). Because of these assumptions, we adopted the term $\mathrm{K}_{\mathrm{F}}$ (formation constant), as used by Weisiger et al. (15), rather than the customary association constant, Ka, to describe binding. Thus:

$$
K_{F}=\left(B-B_{f}\right) /\left(B_{f}\left([\text { albumin }]-B+B_{f}\right)\right)
$$

HRP standardization ( $k$ p). Stock solutions of bilirubin in $\mathrm{NaOH}$ or DMSO were protected from light and used within $1 \mathrm{~h}$. Appropriate volumes were added to $2.8 \mathrm{~mL}$ of medium without albumin, to reach final bilirubin concentrations of 1,2 , and $3 \mu \mathrm{M}$, and the concentration of bilirubin determined spectrophotometrically (Beckman DU 640 spectrophotometer) assuming $\varepsilon^{1 \mathrm{~cm}}=47,500$ per mol at $440 \mathrm{~nm}(16)$. Then $10 \mu \mathrm{L}$ of $1.0 \% \mathrm{H}_{2} \mathrm{O}_{2}$ and $10 \mu \mathrm{L}$ of diluted HRP $\left(1.65 \times 10^{-2} \mu \mathrm{g} / \mathrm{mL}\right)$ were added and the cuvette inverted twice without shaking the supersaturated solution. $\Delta \mathrm{A}_{440 \mathrm{~nm}}$ was recorded for 30-60 s and $\mathrm{kp}$ calculated as described above. Using the same (albumin-free) medium used for $\mathrm{B}_{\mathrm{f}}$ determination, 5 replicates were run at each of 2-3 HRP concentrations, and the 10-15 measurements averaged to determine $\mathrm{kp}$.

Measurement of $\boldsymbol{B}_{f}$. $\mathrm{B}_{\mathrm{f}}$ was measured using undiluted samples to avoid alteration in $\mathrm{K}_{\mathrm{F}}$. Following measurement of $\mathrm{A}_{0}$ at the appropriate wavelength, $5 \mu \mathrm{L}$ of $1.0 \% \mathrm{H}_{2} \mathrm{O}_{2}$ and 5-20 $\mu \mathrm{L}$ HRP (final concentration $0.6-2.5 \mu \mathrm{g} / \mathrm{mL}$ ) were added to $3 \mathrm{~mL}$ bilirubin-albumin solution. The cuvette was inverted twice and $\Delta \mathrm{A}$ measured for $30 \mathrm{~s}$. The HRP concentration was adjusted to produce a $\Delta \mathrm{A}$ of $10-20 \%$ over $1 \mathrm{~min}$. Triplicate determinations were performed at each of 2 to 3 peroxidase concentrations $(0.6,1.2$, and/or 2.5 $\mu \mathrm{g} / \mathrm{mL}$ ) and the steady state $B_{\mathrm{f}}$ was calculated as described above. The equilibrium $\mathrm{B}_{\mathrm{f}}$ was then calculated from formula 5 .

Comparison of peroxidase and ultrafiltration methods using HSA. $\mathrm{B}_{\mathrm{f}}$ was measured using media of the same composition as those used in ultrafiltration studies (15) $(250 \mathrm{mM}$ sucrose $+50 \mathrm{mM} \mathrm{KCl}$ or $350 \mathrm{mM}$ sucrose without chloride, HEPES $20 \mathrm{mM}, \mathrm{pH} 7.4$, and variable HSA concentration). The $\mathrm{B} / \mathrm{A}$ ratio was maintained at 0.2 . Our studies were performed at $37^{\circ} \mathrm{C}$ rather than $25^{\circ} \mathrm{C}$.

Bilirubin binding in solutions containing HSA, BSA, or FCS. In vitro studies of bilirubin toxicity often use bilirubin bound to HSA or BSA, or media containing FCS. The binding of bilirubin to HSA, BSA, and FCS was examined using albumin concentrations of $30 \mu \mathrm{M}$, and varying B, in PBS and DMEMHG, $\mathrm{pH} 7.4$, at $37^{\circ} \mathrm{C}$ in the dark.

Bilirubin stability in solutions without or with albumin. We evaluated the effect of bilirubin solvent (0.01 N NaOH or DMSO) on aqueous stability and $\mathrm{kp}$ determination in DMEMHG and $\mathrm{PBS}, \mathrm{pH} 7.4,37^{\circ} \mathrm{C}$. Final bilirubin concentrations of 1,2 , and $3 \mu \mathrm{M}$ were confirmed by measuring absorbance at $440 \mathrm{~nm}$, and stability was determined by monitoring $\Delta \mathrm{A}_{440}{ }^{\circ} \mathrm{Kp}$ was measured as noted above. The stability of bilirubin-BSA solutions $(\mathrm{B} / \mathrm{A}$ ratio $=0.3)$ was evaluated by monitoring $\mathrm{A}_{468}$ over $24 \mathrm{~h}$.

Other factors affecting $\mathrm{Kp}$ and bilirubin binding to BSA. Unless otherwise noted, the remaining studies were performed in DMEMHG medium, $\mathrm{pH} 7.4$, at $37^{\circ} \mathrm{C}$ using $30 \mu \mathrm{M}$ BSA.

The effects of inorganic anions on binding were studied at a B/A ratio of 0.2. Sodium salts of $\mathrm{Cl}^{-}, \mathrm{Br}^{-}$, or $\mathrm{SO}_{4}^{-}$were added to $250 \mathrm{mM}$ sucrose, containing $20 \mathrm{mM}$ HEPES; HEPES was omitted from studies of phosphate.

The effects of impurities in commercial bilirubin on $\mathrm{kp}$ and $\mathrm{B}_{\mathrm{f}}$ determinations were determined by comparison with purified bilirubin. The effect of light (1000 lux) on $\mathrm{B}_{\mathrm{f}}$ was evaluated using $60 \mu \mathrm{M}$ BSA and $12 \mu \mathrm{M}$ bilirubin in DMEMHG. The solution flask was placed $10 \mathrm{~cm}$ below a POLILUX 4000 58WT8 fluorescent lamp in a biologic safety cabin (Model-VBH72 MP/99; Steril, Milan, Italy). After 15,30 , and 60 min light exposure at $25^{\circ} \mathrm{C}, \mathrm{B}_{\mathrm{f}}$ was measured at $37^{\circ} \mathrm{C}$

The effects of temperature were studied at $25^{\circ} \mathrm{C}$ and $37^{\circ} \mathrm{C}$. Kp was determined at bilirubin concentrations of 1.8 and $3.5 \mu \mathrm{M}$. $\mathrm{B}_{\mathrm{f}}$ was measured using $60 \mu \mathrm{M}$ BSA or HSA and B/A ratios of 0.23 and 0.17 , respectively.

The effects of $\mathrm{pH}$ on $\mathrm{kp}$ and on binding by HSA and BSA were evaluated at $\mathrm{pH} 7.4$ and 8.0. The $\mathrm{pH}$ was adjusted by addition of $0.01 \mathrm{~N} \mathrm{HCl}$ or $\mathrm{NaOH}$. Effects on $\mathrm{B}_{\mathrm{f}}$ were assessed at a $\mathrm{B} / \mathrm{A}$ ratio of 0.3 .

The effect of commonly used tissue culture additives (streptomycin, penicillin, glutamine) on binding were studied in DMEMHG using BSA, B/A 0.2 at $37^{\circ} \mathrm{C}$.

Statistical analysis. Results are expressed as mean \pm SD of three to five assays per condition. Statistical analysis was performed using ANOVA combined with Student's two-tailed $t$ test. Differences among the conditions were considered significant at $p<0.05$.

\section{RESULTS}

Comparison of the peroxidase and ultrafiltration methods with HSA (Fig. 1). HEPES buffer, used for ultrafiltration, inhibited HRP activity, resulting in a kp an order of magnitude lower than in PBS. This required a higher concentration of HRP for measuring $B_{f}$ in the presence of albumin, but the calculated $\mathrm{B}_{\mathrm{f}}$ in a control serum (60 $\mu \mathrm{M}$ BSA, $12 \mu \mathrm{M}$ B) was the same with either HEPES or PBS buffer $(18.9 \pm 1.7 \mathrm{nM}$ versus $19.2 \pm 0.3 \mathrm{nM}$, respectively).

Data obtained with the peroxidase method confirmed the findings of Weisiger et al. (15). The affinity of HSA for 

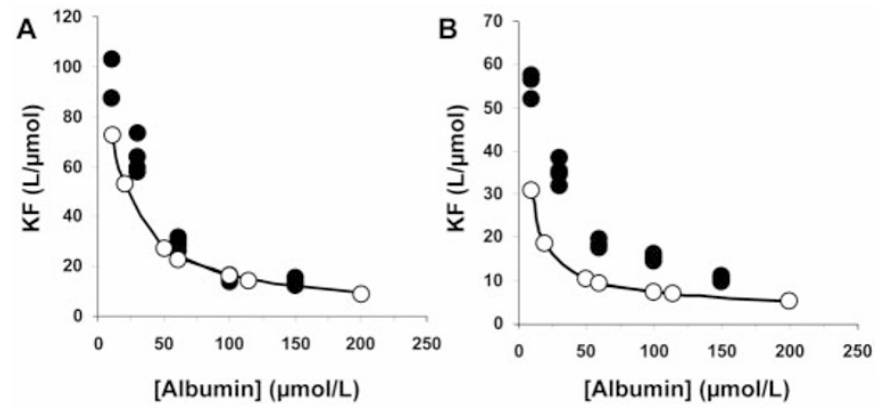

Figure 1. Effect of HSA concentration on the binding affinity $\left(\mathrm{K}_{\mathrm{F}}\right)$ of bilirubin, $37^{\circ} \mathrm{C}$, in the absence $(A)$ or presence $(B)$ of $50 \mathrm{mM} \mathrm{KCl}$. Data are compared with reported $\mathrm{K}_{\mathrm{F}}$ values determined in identical media by ultrafiltration (15). The bilirubin/albumin molar ratio was maintained at 0.2. Peroxidase method $(\bullet)$, ultracentrifugation method $(\bigcirc)$.

bilirubin decreased with increasing albumin concentration and with the addition of chloride (Fig. 1). In the absence of chloride, at HSA concentrations of $60 \mu \mathrm{M}$ or above, the peroxidase and ultrafiltration methods yielded nearly identical results. At lower HSA concentrations, especially in the presence of chloride, the peroxidase method yielded a somewhat higher $\mathrm{K}_{\mathrm{F}}$ than had ultrafiltration, but the patterns were similar.

Comparison of $K_{F}$ for HSA and BSA using the peroxidase method. The effects of albumin and electrolyte concentrations on bilirubin binding to BSA had unique features (Table 1). In the absence of chloride, $\mathrm{K}_{\mathrm{F}-\mathrm{HSA}}$ was about two times higher than $\mathrm{K}_{\mathrm{F}-\mathrm{BSA}}$ at each albumin concentration $(1.6 \times$ at $150 \mu \mathrm{M}$ to $2.7 \times$ at $10 \mu \mathrm{M})$. However, in the presence of $50 \mathrm{mM} \mathrm{Cl}^{-}$, the ratio $\mathrm{K}_{\mathrm{F}-\mathrm{HSA}} / \mathrm{K}_{\mathrm{F}-\mathrm{BSA}}$ increased from $3 \times$ at $150 \mu \mathrm{M}$ to about $10 \times$ at $10 \mu \mathrm{M}$ albumin. With BSA, the dilution effect was mitigated by $50 \mathrm{mM} \mathrm{Cl}^{-}$. In the presence of chloride anion, $\mathrm{K}_{\mathrm{F}-\mathrm{HSA}}$ increased $7 \times$ when albumin was diluted from $150 \mu \mathrm{M}$ to $10 \mu \mathrm{M}$, whereas $\mathrm{K}_{\mathrm{F}-\mathrm{BSA}}$ increased less than $2 \times$ and remained nearly constant with BSA concentrations of 60 $\mu \mathrm{M}$ or higher. However, the effect of chloride on BSA binding was substantial. With HSA, chloride decreased $\mathrm{K}_{\mathrm{F}}$ about $40 \%$ at all HSA concentrations, whereas $\mathrm{K}_{\mathrm{F}-\mathrm{BSA}}$ decreased 3-fold with $150 \mu \mathrm{M}$ BSA and more than 6-fold with albumin concentrations of $30 \mu \mathrm{M}$ or lower.

$B_{f}$ measurements in culture media containing BSA, HSA, or $10 \%$ FCS. In vitro studies of bilirubin toxicity often use bilirubin bound to HSA or BSA, and many cell cultures

Table 1. Effect of albumin concentration and chloride anion on bilirubin binding by HSA and BSA

\begin{tabular}{|c|c|c|c|c|}
\hline \multirow{3}{*}{$\begin{array}{c}\text { [Albumin] } \\
(\mu \mathrm{M})\end{array}$} & \multicolumn{4}{|c|}{$\mathrm{K}_{\mathrm{F}}\left(\times 10^{6} \mathrm{M}^{-1}\right)$} \\
\hline & \multicolumn{2}{|c|}{ HSA } & \multicolumn{2}{|c|}{ BSA } \\
\hline & $\mathrm{No} \mathrm{Cl}^{-}$ & $+50 \mathrm{mM} \mathrm{Cl}^{-}$ & $\mathrm{No} \mathrm{Cl}^{-}$ & $+50 \mathrm{mM} \mathrm{Cl}^{-}$ \\
\hline 10 & $107 \pm 12$ & $61.3 \pm 9.5$ & $39.4 \pm 5.3$ & $6.2 \pm 0.6$ \\
\hline 30 & $55.7 \pm 6.0$ & $31.5 \pm 2.4$ & $28.7 \pm 7.6$ & $4.4 \pm 0.9$ \\
\hline 60 & $26 \pm 1.6$ & $17.0 \pm 0.8$ & $13.9 \pm 1.6$ & $3.7 \pm 0.4$ \\
\hline 100 & $15.9 \pm 1.1$ & $13.8 \pm 0.6$ & $9.6 \pm 1.8$ & $3.1 \pm 0.3$ \\
\hline 150 & $16.0 \pm 1.3$ & $9.6 \pm 0.6$ & $10.0 \pm 0.8$ & $3.3 \pm 0.2$ \\
\hline
\end{tabular}

$\mathrm{K}_{\mathrm{F}}$ was calculated from $\mathrm{B}_{\mathrm{f}}$ values determined by the peroxidase method, using a constant $\mathrm{B} / \mathrm{A}$ ratio of 0.2 . The buffer (20 mM HEPES, pH 7.4) contained either $350 \mathrm{mM}$ sucrose or $250 \mathrm{mM}$ sucrose $+50 \mathrm{mM} \mathrm{KCl}$. Data are expressed as mean $\pm \mathrm{SD}$ of three experiments. require media containing $\mathrm{FCS}$. We, therefore, compared the binding of bilirubin to HSA, BSA, and FCS in DMEMHG.

Addition of $\mathrm{H}_{2} \mathrm{O}_{2}$ alone to DMEMHG with $10 \%$ bilirubinFCS revealed intrinsic oxidase activity that followed saturation kinetics, with a $\mathrm{V}_{\max }$ of $0.07 \Delta \mathrm{A}_{468} /$ min at about $20 \mu \mathrm{M}$ bilirubin (data not shown). This background oxidation rate, which was not diminished by pretreating the medium with a heme-adsorbing resin, was subtracted from the oxidation rate obtained with added HRP to obtain the corrected oxidation rate:

$$
\Delta A / \min _{\text {total }}-\Delta A / \min _{\mathrm{H}_{2} \mathrm{O}_{2}}=\Delta A / \min _{\text {corrected }}
$$

Background oxidation was not observed when either HSA or BSA was added to DMEMHG in the absence of FCS.

Incubation of bilirubin/BSA in DMEMHG in the dark at $37^{\circ} \mathrm{C}$ resulted in a $13 \%$ decay of bilirubin $\left(\Delta \mathrm{A}_{468}\right)$ in $24 \mathrm{~h}$ but only $7 \%$ over $6 \mathrm{~h}$. By contrast, there was no decrease in $\mathrm{A}_{468}$ when bilirubin/BSA was dissolved in PBS.

Titrations of bilirubin using a constant albumin concentration of $30 \mu \mathrm{M}$ in DMEMHG (Fig. 2) revealed a greater binding affinity with HSA than with either BSA or FCS. B was similar with $\mathrm{BSA}$ and FCS up to a B/A ratio of 0.5 but rose steeply at higher B/A ratios with FCS. Addition of glutamine (2 mM), streptomycin (100 mg/L), and $1 \%$ (vol/vol) penicillin $(100,000 \mathrm{U} / \mathrm{L})$ to culture medium $\left(\mathrm{B} / \mathrm{A}\right.$ 0.2) did not alter $\mathrm{B}_{\mathrm{f}}$ (37 $\pm 5 \mathrm{nM}$ versus $39 \pm 7 \mathrm{nM}$ in controls).

Effect of inorganic anions on binding affinity of BSA for bilirubin. The addition of $118 \mathrm{mM} \mathrm{NaCl}$ increased $\mathrm{B}_{\mathrm{f}}$ from 10 to $179 \mathrm{nM}$ and, as shown in Figure $3 A$, decreased $\mathrm{K}_{\mathrm{F}}$ from 28.7 to $1.3 \mu \mathrm{M}^{-1}$. Bromide behaved similarly (data not shown). Divalent sulfate anion decreased $\mathrm{K}_{\mathrm{F}}$ more than chloride, with inhibition of bilirubin binding by $97 \%$ or more at sulfate concentrations of $50 \mathrm{mM}$ or higher. In contrast, phosphate $(50 \mathrm{mM}, \mathrm{pH} 7.4)$ produced only a $30 \%$ reduction in $\mathrm{K}_{\mathrm{F}}$.

For each anion, $\log \mathrm{K}_{\mathrm{F}}$ was negatively correlated with the square root of ionic strength (Fig. 3B). Chloride, bromide (not shown), and sulfate produced similar decreases in binding with increasing ionic strength; the effect of phosphate was much less at all ionic strengths.

Effect of bilirubin solvent and medium on bilirubin stability and Kp determination. DMSO is frequently used as a bilirubin solvent for in vitro toxicity studies, while $\mathrm{NaOH}$ is usually

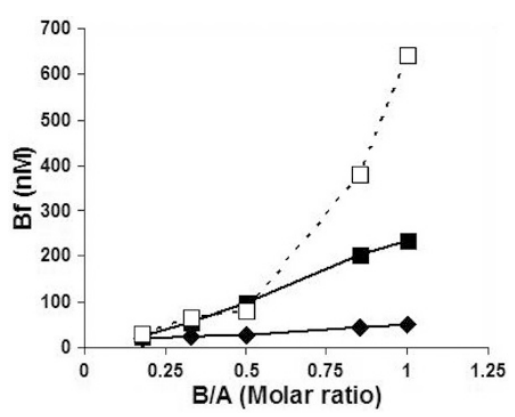

Figure 2. Effect of albumin species on the concentration of unbound bilirubin $\left(\mathrm{B}_{\mathrm{f}}\right)$ at various bilirubin/albumin (B/A) molar ratios, comparing FCS ( $\square$ ), BSA (ם), and HSA ( ), each $30 \mu \mathrm{M}$. Medium was DMEMHG. $\mathrm{B}_{\mathrm{f}}$ was measured at $37^{\circ} \mathrm{C}, \mathrm{pH}=7.4$, using HRP concentrations of $0.6,1.2$, and 2.5 $\mu \mathrm{g} / \mathrm{mL}$. 

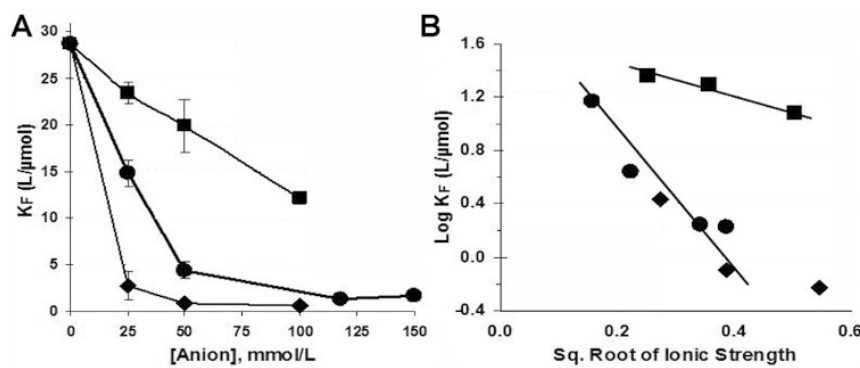

Figure 3. Effect of sodium salts of different anions on binding of bilirubin to BSA. The experiments were performed at $37^{\circ} \mathrm{C}$ in $250 \mathrm{mM}$ sucrose, $20 \mathrm{mM}$ HEPES, $\mathrm{pH} 7.4$, containing $30 \mu \mathrm{M}$ BSA at a constant bilirubin/albumin molar ratio of 0.2 . Data represent the mean $\pm \mathrm{SD}$ of three experiments. For 50 and $100 \mathrm{mM}$ phosphate $v s$ no phosphate, $p<0.02$ and $p<0.002$, respectively. For each concentration of chloride or sulfate $v s$ no anion, $p<0.001$. Phosphate $(\square)$, chloride $(\bullet)$, sulfate $(\bullet)$.

used for peroxidase standardization. Bilirubin dissolved in DMSO precipitated when added to DMEMHG, so DMSO could not be used to determine $\mathrm{kp}$ in this medium. In PBS, spontaneous absorbance decay was greater for bilirubin dissolved in $\mathrm{NaOH}(\Delta \mathrm{A} / \mathrm{min}=0.0028)$ than in DMSO $(\Delta \mathrm{A} / \mathrm{min}=0.0014)$.

Kp values in PBS were not significantly different for bilirubin dissolved with $\mathrm{NaOH}\left(463 \pm 53 \mathrm{~mL} \cdot \mu \mathrm{g}^{-1}\right.$. $\left.\min ^{-1}\right)$ or DMSO $\left(491 \pm 30 \mathrm{~mL} \cdot \mu \mathrm{g}^{-1} \cdot \min ^{-1}\right)$ and were unaffected by bilirubin concentration $(1,2$, or $3 \mu \mathrm{M})$. Kp did not differ significantly between DMEMHG (445 \pm 41 $\left.\mathrm{mL} \cdot \mu \mathrm{g}^{-1} \cdot \mathrm{min}^{-1}\right)$ and PBS $\left(463 \pm 53 \mathrm{~mL} \cdot \mu \mathrm{g}^{-1} \cdot \min ^{-1}\right)$ when bilirubin was dissolved in $\mathrm{NaOH}$.

Effect of bilirubin purity and light exposure on binding to BSA in DMEMHG. Purified and commercial bilirubin yielded similar $\mathrm{kp}$ values $(439 \pm 24$ versus $450 \pm 44$ $\mathrm{mL} \cdot \mu \mathrm{g}^{-1} \cdot \min ^{-1}$, respectively) and $\mathrm{B}_{\mathrm{f}}$ values $(21.1 \pm 1.8$ versus $21.2 \pm 0.9 \mathrm{nM}$, respectively). After 15, 30, and $60 \mathrm{~min}$ exposure of bilirubin-BSA to intense light, $\mathrm{B}_{\mathrm{f}}$ remained unchanged $(25.0 \pm 1.1 \mathrm{nM}$ at time 0 versus $25.4 \pm 0.6 \mathrm{nM}$ after $1 \mathrm{~h})$ despite a $14 \%$ drop in total bilirubin.

Effect of temperature on Kp and $\boldsymbol{B}_{\boldsymbol{f}}$ In DMEMHG, the $\mathrm{kp}$ at $25^{\circ} \mathrm{C}, 282 \pm 34 \mathrm{~mL} \cdot \mu \mathrm{g}^{-1} \cdot \mathrm{min}^{-1}$, was much lower than at $37^{\circ} \mathrm{C}, 445 \pm 41 \mathrm{~mL} \cdot \mu \mathrm{g}^{-1} \cdot \mathrm{min}^{-1}$. In the small sample size studied $(n=5)$, we did not observe a temperature effect on binding to BSA $\left(\mathrm{B}_{\mathrm{f}}\right.$ measured at $25^{\circ} \mathrm{C}$ was $41.3 \pm 4.8 \mathrm{nM}$ versus $34.5 \pm 5.6 \mathrm{nM}$ at $\left.37^{\circ} \mathrm{C}, p=0.07\right)$. Bilirubin binding to HSA decreased slightly at the higher temperature $\left(\mathrm{B}_{\mathrm{f}}=22.8\right.$ $\pm 1.6 \mathrm{nM}$ at $25^{\circ} \mathrm{C}$ versus $31.3 \pm 6.1 \mathrm{nM}$ at $\left.37^{\circ} \mathrm{C}, p=0.03\right)$, consistent with observations of Jacobsen (20).

Effect of $p H$ on Kp and $B_{f}$ in DMEMHG. Tissue culture is frequently buffered by a $\mathrm{CO}_{2}$-bicarbonate system, resulting in an increased $\mathrm{pH}$ when removed from the $\mathrm{CO}_{2}$ atmosphere. The $\mathrm{kp}$ of $463 \pm 31$ at $\mathrm{pH} 7.4$ fell to $402 \pm 29 \mathrm{~mL} \cdot \mu \mathrm{g}^{-1} \cdot \mathrm{min}^{-1}$ at 8.0 $(p<0.03)$. Nonetheless, $\mathrm{B}_{\mathrm{f}}$ values for bilirubin-BSA did not differ between $\mathrm{pH} 7.4$ and $8.0(51 \pm 9.0$ and $48 \pm 8.0 \mathrm{nM}$, respectively). Similar results have been reported using HSA $(21,22)$.

\section{DISCUSSION}

Our data confirm the effects of albumin and chloride concentration on bilirubin binding to HSA (15). There was good agreement with the ultrafiltration data (15), especially at HSA concentrations of $60 \mu \mathrm{M}$ or higher in the absence of chloride. At low HSA concentrations, the peroxidase method yielded somewhat higher $\mathrm{K}_{\mathrm{F}}$ values than observed with ultrafiltration (15). This difference may be due in part to an albumin gradient created by ultracentrifugation, engendering higher HSA concentrations at the interface of the retentate with the filter. This would increase filtered bilirubin, yielding a higher apparent $B_{f}$ and lower $\mathrm{K}_{\mathrm{F}}$.

The range of $\mathrm{K}_{\mathrm{F}}$ values for HSA observed under various conditions in our study $\left(6.9 \times 10^{6} \mathrm{M}^{-1}\right.$ to $1.1 \times 10^{8} \mathrm{M}^{-1}$, Table 1) reflects the range of association constants reported in the literature using a variety of experimental techniques. Interestingly, the higher published values $\left(\mathrm{K}_{\mathrm{F}}>10^{8} \mathrm{M}^{-1}\right)$ were performed with very dilute albumin solutions $(7,10)$, whereas the lower $\mathrm{K}_{\mathrm{F}}$ of $6.7 \times 10^{6} \mathrm{M}^{-1}$, reported by Lamola et al. (8), used $440 \mu \mathrm{M}$ HSA. The effect of albumin concentration on binding was far greater with HSA than with BSA (Table 1).

Our studies extend to BSA the previously reported inhibitory effect of $50 \mathrm{mM}$ chloride anion on HSA binding (15) and also measured the effect of higher (physiologic) chloride concentrations. Chloride, bromide, and sulfate have the same effect on binding when analyzed as a function of ionic strength. Dehydration has been implicated in potentiating kernicterus, but variations in anion concentration within the range observed clinically should have little impact on bilirubin binding (Fig. 3A). The effect of phosphate is much smaller though still related to ionic strength, confirming the findings of Jacobsen (20). In contrast, Weisiger et al. (15) found that gluconate anion had no effect on bilirubin binding. Although the inhibition of organic anion binding by chloride roughly parallels the extent of binding by chloride $(23,24)$, chloride binds to many more sites on albumin than does bilirubin (24). Thus, the relative roles of ionic strength, allosteric effects, and specific binding competition with anions remain uncertain.

A potential error in measuring $B_{f}$ with the peroxidase method is that the HRP activity (kp) must be standardized with supersaturated bilirubin solutions. Aggregation of bilirubin might impair its oxidation, yielding a falsely low $\mathrm{kp}$ and overestimate of $\mathrm{B}_{\mathrm{f}}$. However, we found no differences in $\mathrm{kp}$ values measured at bilirubin concentrations of 1,2 , and $3 \mu \mathrm{M}$, suggesting that aggregation did not affect oxidation rates during the brief duration of the assay.

Water-soluble photoisomers, which form rapidly when bilirubin is exposed to light, cannot be distinguished from native ZZ-bilirubin IX $\alpha$ by either light absorbance or diazo reaction, but are thought to bind less tightly to albumin (25). Although photoisomer concentration was not determined, we found no effect on $\mathrm{B}_{\mathrm{f}}$ of short-term, intense exposure of bilirubin-BSA to light. This result is explicable only if the photoproducts are bound to the bilirubin site on BSA, contribute to absorbance at $440 \mathrm{~nm}$, and/or are substrates oxidized by HRP. Itoh et al. (26) previously demonstrated that the initial rate of the peroxidase reaction with HSA is not accelerated by either (ZE)photobilirubin or (EZ)-cyclobilirubin when present at clinically relevant concentrations. 
Most reported in vitro studies examining bilirubin effects or toxicity use HSA or BSA as a bilirubin stabilizer or donor, but rarely measure $B_{f}$ and often use initial bilirubin concentrations that greatly exceed physiologic or pathologic significance (27). Even fewer studies measured the more meaningful equilibrium concentration of bilirubin during or after incubation $(22,28)$. Ostrow et al. (27) recently calculated the $\mathrm{B}_{\mathrm{f}}$ from molar bilirubin/albumin ratios (B/A) reported in several studies by applying ultrafiltration-determined binding constants for HSA in similar media (15). This study confirms, however, that calculated $\mathrm{B}_{\mathrm{f}}$ 's are unreliable since binding affinity varies with albumin species, albumin concentration, and the buffer medium used.

Tissue culture media typically contain $10 \%$ FCS, providing a BSA concentration of about $33 \mu \mathrm{M}$. Thus, bilirubin can be added directly to the medium rather than replacing medium with albumin solution. However, when using FCS, we found it important to correct for background oxidase activity. We also confirmed that commonly used culture medium additives, glutamine, streptomycin, and penicillin, do not alter binding.

In conclusion, our goal was to validate a practical method for measuring $B_{f}$ and to adapt the method for studies using tissue culture media. The peroxidase method yielded $\mathrm{K}_{\mathrm{F}}$ values concordant with ultrafiltration data (15) obtained with nearly identical experimental conditions, and consistent with published values for $\mathrm{K}_{\mathrm{F}}$. Compared with HSA, BSA has a lower binding affinity, greater sensitivity to chloride and less sensitivity to temperature. Our findings emphasize the need to measure HRP activity (kp) and $B_{f}$ under the same conditions and in the same media used experimentally. We recommend that $\mathrm{B}_{\mathrm{f}}$ be measured under steady state or equilibrium conditions in all studies in which albumin is used as a reservoir for bilirubin. This would facilitate interpretation of dose-response relationships and improve comparisons of in vitro studies conducted in different laboratories.

\section{REFERENCES}

1. Ahlfors CE, Wennberg RP 2004 Bilirubin-albumin binding and neonatal jaundice. Semin Perinatol 28:334-339

2. Wennberg RP, Ahlfors CE, Bhutani VK, Johnson LH, Shapiro SM 2006 Toward understanding kernicterus: a challenge to improve the management of jaundiced newborns. Pediatrics 117:474-485
3. Ihara H, Hashizume N, Shimizu N, Aoki T 1999 Threshold concentration of unbound bilirubin to induce neurological deficits in a patient with type I CriglerNajjar syndrome. Ann Clin Biochem 36:347-352

4. Levine RL 1979 Bilirubin: worked out years ago? Pediatrics 64:380-385

5. Robinson PJ, Rapoport SI 1987 Binding effect of albumin on uptake of bilirubin by brain. Pediatrics 79:553-558

6. McDonagh AF, Maisels MJ 2006 Bilirubin unbound: deja vu all over again? Pediatrics 117:523-525

7. Levine RL 1977 Fluorescence-quenching studies of the binding of bilirubin to albumin. Clin Chem 23:2292-2301

8. Lamola AA, Eisinger J, Blumberg WE, Patel SC, Flores J 1979 Flurorometric study of the partition of bilirubin among blood components: basis for rapid microassays of bilirubin and bilirubin binding capacity in whole blood. Anal Biochem 100:25-42

9. Sato H, Honoré B, Brodersen R 1988 Multiple binding of bilirubin to human albumin and cobinding with laurate. Arch Biochem Biophys 260:811-821

10. Brodersen R 1979 Binding of bilirubin to albumin; implications for prevention of bilirubin encephalopathy in the newborn. CRC Crit Rev Clin Lab Sci 11:305-399

11. Faerch T, Jacobsen J 1975 Determination of association and dissociation rate constants for bilirubin-bovine serum albumin. Arch Biochem Biophys 168:351-357

12. Blauer G, Lavie E, Silfen J 1977 Relative affinities of bilirubin for serum albumins from different species. Biochim Biophys Acta 492:64-69

13. Reed RG 1977 Kinetics of bilirubin binding to bovine serum albumin and the effects of palmitate. J Biol Chem 252:7483-7487

14. Ahlfors CE 1981 Effect of serum dilution on apparent unbound bilirubin concentration as measured by the peroxidase method. Clin Chem 27:692-696

15. Weisiger RA, Ostrow JD, Koehler RK, Webster CC, Mukerjee P, Pascolo L, Tiribelli C 2001 Affinity of human serum albumin for bilirubin varies with albumin concentration and buffer composition: results of a novel ultrafiltration method. J Biol Chem 276:29953-29960

16. Jacobsen J, Wennberg RP 1974 Determination of unbound bilirubin in the serum of newborns. Clin Chem 20:783-789

17. Ahlfors CE 2000 Measurement of plasma unbound unconjugated bilirubin. Anal Biochem 279:130-135

18. McDonagh AF, Assisi F 1972 The ready isomerization of bilirubin-IX $\alpha$ in aqueous solution. Biochem J 129:797-800

19. Delincee H, Radola BJ 1975 Fractionation of horseradish peroxidase by preparative isoelectric focusing, gel chromatography and ion-exchange chromatography. Eur J Biochem 52:321-330

20. Jacobsen J 1977 Studies of the affinity of human serum albumin for binding of bilirubin at different temperatures and ionic strength. Int J Pept Protein Res 9:235239

21. Jacobsen J, Brodersen R 1976 The effect of $\mathrm{pH}$ on albumin-bilirubin binding affinity. Birth Defects Orig Artic Ser 12:175-178

22. Wennberg RP 1988 The importance of free bilirubin acid salt in bilirubin uptake by erythrocytes and mitochondria. Pediatr Res 23:443-447

23. Klotz IM 1950 The nature of some ion-protein complexes. Cold Spring Harb Symp Quant Biol 14:97-112

24. Scatchard G, Scheinberg IH, Armstrong SH Jr 1950 Physical chemistry of protein solutions. IV. The combination of human serum albumin with chloride ion. J Am Chem Soc 72:535-540

25. Lamola AA, Flores J, Blumberg WE 1983 Binding of photobilirubin to human serum albumin. Estimate of the affinity constant. Eur J Biochem 132:165-169

26. Itoh S, Yamakawa T, Onishi S, Isobe K, Manabe M, Sasaki K 1986 The effect of bilirubin photoisomers on unbound-bilirubin concentrations estimated by the peroxidase method. Biochem J 239:417-421

27. Ostrow JD, Pascolo L, Tiribelli C 2003 Reassessment of the unbound concentration of unconjugated bilirubin in relation to neurotoxicity in vitro. Pediatr Res 54:98-104

28. Nelson T, Jacobsen J, Wennberg RP 1974 Effect of $\mathrm{pH}$ on the interaction of bilirubin with albumin and tissue culture cells. Pediatr Res 8:963-967 